\title{
PENGENALAN APLIKASI MEMRISE UNTUK MENINGKATKAN KOMPETENSI BAHASA INGGRIS MELALUI TOEFL
}

\author{
Eva Nurul Candra, Hermariyanti Kusumadewi \\ Pendidikan Bahasa Inggris, Fakultas Bahasa dan Seni, \\ Universitas Indraprasta PGRI Jakarta \\ evanurulcandra@yahoo.com,Kususmadewi@gmail.com
}

\begin{abstract}
Abstrak
Tujuan diadakannya pengenalan aplikasi Memrise ini adalah untuk meningkatkan kompetensi para guru Bahasa Inggris dalam mempelajari tes - tes TOEFL guna mendukung kemampuan TOEFL mereka. Pengenalan aplikasi ini dilaksanakan di SMPN 09 dan SMPN 34 Kota Bekasi. Metode yang digunakan dalam penelitian ini adalah metode kuantitatif dan kualitatif desktiptif dengan memberikan pre-test dan post-test TOEFL. Sample dan populasi berasal dari gur-guru Bahasa Inggris di SMP 9 dan 34 Bekasi. Hasil dari pengenalan aplikasi ini adalah ditunjukkan dari hasil post test. Hasil post test menunjukkan bahwa aplikasi memrise berperan dalam menambah pengetahuan para guru.
\end{abstract}

Kata kunci : aplikasi memrise, tes TOEFL

\begin{abstract}
The aim of the memrise training is to enhance the teacher competence in doing a TOEFL test. This training was done in SMPN 9 \& 34 Bekasi. Kuantitatif dan kuanlitatif method was used in this training. The trainer took pre-test and post - test in order seek the effect of the application. Sample and pupolation took from the teacher in SMP $9 \& 34$ Bekasi. The result shown in the table of post test. It shown that memrise application gave a significant benefit for the teacher in doing TOEFL tes.
\end{abstract}

Key words : Memrise application, TOEFL test

\section{PENDAHULUAN}

Dalam era globalisasi saat ini, keberadaan bahasa Inggris dianggap penting karena merupakan bahasa yang dipakai dalam komunikasi internasional. Di Indonesia sendiri, walaupun posisi bahasa Inggris bukan sebagai bahasa kedua, bahasa Inggris adalah bahasa asing pertama yang diajarkan di sekolah formal mulai dari tingkat Sekolah Dasar sampai Perguruan Tinggi. Maka dari itu penting bagi masyarakat Indonesia untuk mempelajarai bahasa Inggris.

Tujuan pembelajaran bahasa adalah dapat berkomunikasi baik lisan maupun tertulis dengan bahasa yang dipelajari. Ada empat ketrampilan yang harus dikuasai saat mempelajari bahasa Inggris, adapun ketrampilan tersebut adalah menyimak (listening), berbicara (speaking), membaca (reading), dan menulis (writing). Ketrampilan berbahasa ini berkaitan antara satu dengan 
yang lain dan juga untuk mencapai tujuan belajar bahasa juga pembelajar idealnya mempelajari komponen bahasa, seperti tatabahasa (structure), kosakata (vocabulary), pengucapan (prunounciation).

Dilihat dari tujuan utama pembelajaran bahasa yang sudah dikemukakan di atas, tujuan pembelajaran bahasa Inggris sendiri di Indonesia adalah membuat siswa dapat mengerti dan paham bacaan ataupun komunikasi secara lisan dan tertulis. Berdasarkan pengamatan penulis, pengajaran bahasa Inggris di Sekolah Dasar mempunyai fokus pada pengenalan kosakata, pemahaman teks sederhana dan pemberian respon pada percakapan sederhana. Oleh karena itu, guru Sekolah Menengah Pertama ( SMP), yang mulai mengajar mata pelajaran secara khusus, diharapkan mempunyai kemampuan dasar bahasa Inggris yang dapat diajarkan kepada siswa.

Pentingnya mempunyai pengetahuan dasar bahasa Inggris, selain dapat menunjang kegiatan mengajar bahasa Inggris di sekolah ternyata bahasa Inggris juga penting dalam menunjang kinerja guru. Guna mempersiapkan diri dalam berbagai tes yang berhubungan dengan kompetensi guru. Banyak tes yang dapat dijadikan tolak ukur kemampuan bahasa Inggris seseorang. Tes seperti ini banyak diperlukan saat melanjutkan pendidikan ke jenjang yang lebih tinggi ataupun mendukung kinerja profesionalitas. Salah satu tes yang akan dihadapi para guru Sekolah Dasar adalah tes TOEFL. Dimana tes ini merupakan tolak ukur apakah guru tersebut berkompeten atau tidak dalam bidang pengajaran.

Ketika para guru SMP dihadapkan dengan latihan tes TOEFL, mereka sering kali mengalami kendala dalam hal waktu, tempat dan tutor. Waktu yang sangat terbatas untuk para guru untuk melatih kemampuan bahasa Inggris mereka menjadikan mereka malas untuk berlatih. Padahal latihan pada pembelajaran bahasa sangatlah penting.

Kendala seperti ini sekarang tidaklah menjadi sebuah masalah besar. Karena sekarang sudah ada sebuah aplikasi di android yang memudahkan para praktisi pendidikan untuk berlatih TOEFL kapanpun dan dimanapun. Aplikasi ini disebut memrise. Memrise Learn Languages Free - Aplikasi Android Terbaik dengan kategori edukasi untuk pembelajaran bahasa inggris, akan tetapi tidak hanya dalam bahasa inggris saja yang difokuskan dalam kursus ini, melainkan banyak bahasa-bahasa lainnya seperti Chinese, French, Italian, Russian, English, German, Portuguse, Spanish, Afrikaans, Akan-Twi, Albanian, American Sign Lnguage (ASL), Ancient Greek, Arabic, Armenian, Azerbaijani, Basque, Belarusian, Bengali, Bosnian, Bulgarian, Cantonese, Cantonese Jyutping, Catalan, Chinese, Croatian, Czech, Danish, Dutch, English, Esperanto, Estonian, Faroese, Flemish, Georgian, Greek, Greenlandic, Hakka, Hindi, Hungarian, Icelandic, Indonesian, Irish, Italian, Japanese, Kanji, Khmer, Korean, Kurdish, Kyrgyz, Ladin, Latin, Latvian, Luxembourgish, Thai, Vietnamese dan masih banyak lagi yang lainnya bahkan hampir semua bahasa didunia ada didalam satu aplikasi ini.

Dengan adanya aplikasi ini dapat memudahkan para guru dalam meningkatkan kemampuan mereka dalam mempelajari tes - tes TOEFL. Tetapi kendala yang lain adalah para guru belum terbiasa menggunakan aplikasi ini. Untuk itu tim abdimas akan mencoba melakukan pelatihan guna meningkatkan kemampuan kompentensi para guru SMP tersebut melalui aplikasi Memriseterhadap kemampuan TOEFL. 


\section{Kajian Pustaka}

1. Pengertian Bahasa Inggris

Menurut Richards (2001:109)

"English languange is always use in a social context, and this applies to both oral and written languange, to both first and second languange use”. Bahasa Inggris sekarang digunakan dalam kehidupan sosial, baik dalam bentuk lisan maupun tertulis, sebagai bahasa pertama dan bahasa kedua. Bahasa Inggris digunakan oleh banyak orang di tiaptiap negara yang berbeda sebagai bahasa pertama atau bahasa kedua.

Lebih lanjut, Freeborn (2006:1) menyatakan bahwa: "English today is a worldwide international languange. It is spoken as a mother tongue by about 400 million people in the British Isles, Canada, the United state of America, Australia and New Zealand. It is a second languange for many others in, for example, India and Pakistan and some African states, where it is used as an official languange in government and education." Bahasa Inggris sekarang ini adalah bahasa internasional di seluruh dunia. Bahasa Inggris digunakan sebagai bahasa ibu oleh kira-kira 400 juta orang di Inggris, Kanada, Amerika, dan New Zealand. Bahasa Inggris juga digunakan sebagai bahasa kedua oleh banyak negara, seperti India dan Pakistan dan di beberapa kesatuan Afrika, yang digunakan sebagai bahasa resmi pada system pemerintahan nya dan pendidikan.

\section{Pengertian TOEFL}

Test of English as a Foreign Language, yang disingkat TOEFL, adalah tes kemahiran berbahasa Inggris bagi orang-orang yang bahasa aslinya bukan Bahasa Inggris, yang diselenggarakan dengan sistem online. Tes ini mengukur tingkat kemampuan berbahasa Inggris, utamanya kemampuan memahami isi teks lisan dan tertulis, baik yang tersirat maupun yang tersurat. Dengan system online ini, semua soal disajikan lewat layar monitor dan dikerjakan langsung pada layar tersebut dengan mengikuti perintah lisan yang diperdengarkan lewat headphone dan/atau perintah tertulis yang tersaji dalam layar. Jadi, dalam mengerjakan tes ini peserta bersandar sepenuhnya pada kerja perangkat peralatan elektronik yang telah tersedia di mejates. Oleh sebab itu, peserta tidak perlu membawa alat tulis apapun untuk mengerjakan tes; bahkan dilarang membawa alat apapun kemeja/tempat duduk tes agar konsentrasi tidak terganggu.

Untuk dapat mengikuti tes online ini, peserta harus memiliki keterampilan komunikasinya, yang terdiri atas: (1) keterampilan dasar mengoperasikan komputer; (2) keterampilan mengakses informasi sesuai dengan prosedur teknis jaringan; dan (3) keterampilan memberikan jawaban terhadap pertanyaan dengan teknik jaringan sesuai dengan perintah. Terkait dengan hal ini, agar mengenali cara kerja tes online ini, para peserta diwajibkan mengikuti paket Tutorial dan mengerjakan Dummy Test (contoh soal) sebelum mengerjakan paket soal.

Paket soal TOEFL terdiri atas dua bagian: Listening (50 butirsoal) dan Reading (50 butirsoal). Bagian tes Listening berlangsung selama 4550 menit dan Reading selama 60 menit. Jadi keseluruhan waktu tes berkisar 105-110 menit. Tidak ada istirahat atau jeda antara kedua bagian tes tersebut. Soal-soal Listening hanya disajikan sekali 
(tidak diulang). Maka ketika peserta telah pindah ke nomor soal berikutnya, dia tidak dapat kembali ke soal sebelumnya. Jadi perbaikan jawaban tidak mungkin dilakukan. Sebaliknya, dalam mengerjakan soal-soal Reading, peserta dapat kembali kesoal-soal sebelumny adalam waktu yang masih tersedia. Maka, perbaikan jawaban soal yang pernah dikerjakan dapat dilakukan jika dikehendaki. Skor masingmasing peserta akan muncul di layar monitor. Skor yang muncul sama dengan jumlah jawaban yang benar; jadi, tidak ada penalti (pengurangan) untuk jawaban yang salah. Oleh sebab itu, peserta seyogyanya menjawab semua soal.

Dari berbagai tes, ada tes yang sudah distandarisasikan. Jenis tes tersebut adalah Standardized Test . Menurut Payne ( 2003 ), tes berstandar adalah " a standardized test is one that is administered and scored under uniform and controlled conditions." Dari definisi mengenai jenis tes di atas, maka tes TOEIC merupakan suatu tes yang harus dikuasai oleh para guru karena tes tersebut merupakan tes yang sudah di standarisasikan oleh Pemerintah dalam mengukur kemampuan mereka memahi Bahasa Inggris.

2. Pengertian Memrise

Memrise Learn Languages

Free - Aplikasi Android Terbaik dengan kategori edukasi untuk pembelajaran bahasa inggris, akan tetapi tidak hanya dalam bahasa inggris saja yang difokuskan dalam kursus ini, melainkan banyak bahasa-bahasa lainnya seperti Chinese, French, Italian, Russian, English, German, Portuguse, Spanish, Afrikaans, Akan-Twi, Albanian, American Sign Lnguage(ASL), Ancient Greek, Arabic, Armenian, Azerbaijani, Basque, Belarusian, Bengali, Bosnian, Bulgarian, Cantonese, Cantonese Jyutping, Catalan, Chinese, Croatian, Czech, Danish, Dutch, English, Esperanto, Estonian, Faroese, Flemish, Georgian, Greek, Greenlandic, Hakka, Hindi, Hungarian, Icelandic, Indonesian, Irish, Italian, Japanese, Kanji, Khmer, Korean, Kurdish, Kyrgyz, Ladin, Latin, Latvian, Luxembourgish, Thai, Vietnamese dan masih banyak lagi yang lainnya bahkan hamper semua bahasa di dunia ada di dalam satu aplikasi ini.

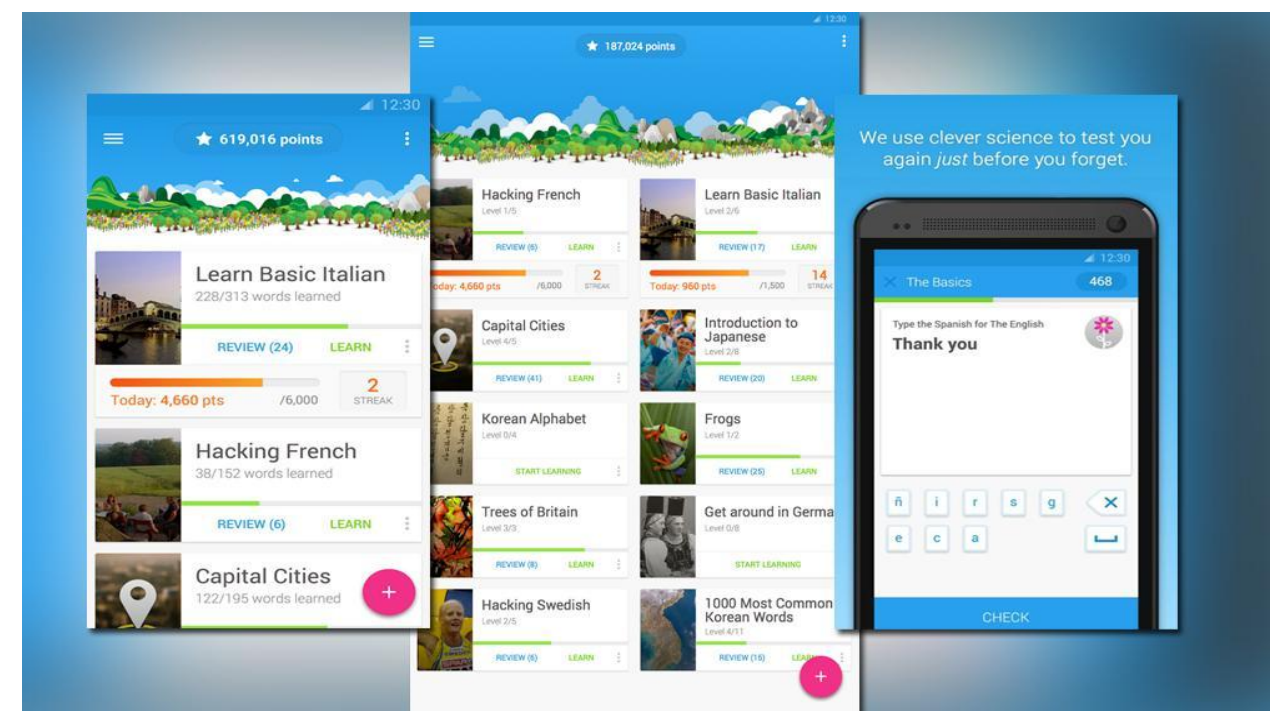


Tidak hanya berhenti dalam pembelajaran Vocabs-nya saja, namun kalian dapat memilih topic pembahasan, topic itu terdiri dariArts \& Literature, Maths \& Science, The Natural World, History \& Geography, Memory Training, Professional and Careers, Standarized tests, Trivia dan Entertainment. Jangan lupa untuk mencob sebuah Kuis dari Aplikasi Android Terbaik ini di hape kalian, jika kalian merasa telah banyak mempelajari modul-modul yang diberikan di Aplikasi ini kenapa tidak langsung uji coba pengetahuan kalian dengan mencoba kuis Trivianya.

Download Memrise sekarang juga dan jadilah orang yang pintar dengan banyak bahasa yang sudah dipelajari dari Aplikasi Android Terbaik ini, dan jangan pernah ketinggalan pembaharuan dari setiap Aplikasi-aplikasi terpopuler dan terbaik dari Jalan Tikus.

KeunggulanMemrise Learn Languages Free:

a. Memiliki database bahasa yang sangatbanyak

b. Pelatihanuntuk SAT, GMAT, TESOL, TOEFL, TOEIC, dantesstandarlainnya

c. KursusRevisiuntuk GCSE, ALevel, IBAC danbanyaklagi

d. Melatih Otak Anda dengan mempelajari sebuah kotabesar, dari sejarah ataupun geografi

e. Terdapat Trivia atau Kuis untuk setiap pembelajaran

\section{Target}

Target dari kegiatan ini adalah meningkatkan kompetensi dan kemampuan bahasa Inggris para guru. Adapapun target peserta pelatihan ini merupakan guru bahasa Inggris SMPN 9 dan SMPN 34 Kota Bekasi, dengan jangka waktu pelaksanaan sebanyak tiga kali pertemuan yang mana pertemuan pertama melakukan pre - test TOEFL, pertemuan kedua pelatihan penggunaan aplikasi memrise dan pertemuan ketiga melakukan post -test TOEFL dengan biaya sebesar empat juta lima ratus ribu rupiah. Materi yang akan disampaikan meliputi pengertian dan konsep serta simulasi penggunaan aplikasi memrise beserta contoh soal - soal TOEFL.

\section{HASIL DAN PEMBAHASAN}

Kegiatan Pengabdian Pada Masyarakat ini dilaksanakan dalam bentuk sosialisasi dan pelatihan terprogram, seperti yang ditunjukkan pada tabel berikut:

Table 5.1 Rincian Kegiatan

\begin{tabular}{|l|l|}
\hline Pertemuan & \multicolumn{1}{|c|}{ Rincian Kegiatan } \\
\hline \multirow{5}{*}{1 Sosialisasi program } \\
\cline { 2 - 3 } & $\begin{array}{l}\text { Materi, diskusi dan } \\
\text { tanya jawab seputar } \\
\text { pembelajaran bahasa } \\
\text { Inggris dan media } \\
\text { pendukung } \\
\text { pembelajaran bahasa } \\
\text { Inggris. }\end{array}$ \\
\cline { 2 - 2 } & $\begin{array}{l}\text { Penggalian konsep- } \\
\text { konsep tentang media } \\
\text { pembelajaran bahasa }\end{array}$ \\
& $\begin{array}{l}\text { Inggris yang kreatif dan } \\
\text { inovatif. }\end{array}$ \\
\cline { 2 - 2 } & $\begin{array}{l}\text { Pelatihan penggunaan } \\
\text { aplikasi memrise yang } \\
\text { dibimbing langsung } \\
\text { oleh pemateri. }\end{array}$ \\
\cline { 2 - 2 } & $\begin{array}{l}\text { Praktek penggunaan } \\
\text { aplikasi memrise dalam } \\
\text { mengerjkaan TOEFL. }\end{array}$ \\
\cline { 2 - 2 } & $\begin{array}{l}\text { Evaluasi program yang } \\
\text { dilakukan di akhir } \\
\text { kegiatan }\end{array}$ \\
\hline
\end{tabular}


Aktivitas - aktivitas yang terjadi pada pelatihan peningkatan kompetensi guru melalui aplikasi memrise terhadap kemampuan TOEFL. Penggunaan aplikasi memrise dalam pembelajaran bahasa Inggris adalah sebagai berikut:

Pada tahap awal kegiatan, peserta dikenalkan pada pengertian bahasa Inggris dan TOEFL, setelah itu diberikan pengertian mengenai konsep berbagai media yang dapat mendukung kegiatan pembelajaran bahasa Inggris. Lalu setelah mereka siap untuk mendapatkan materi mengenai media pembelajaran, kami selaku pemateri menyajikan slide materi mengenai penjelasan aplikasi memrise. Peserta menyimak dengan serius dan membaca secara seksama materi yang sudah diberikan sebelumnya.

Setelah menjelaskan definisi dan teori - teori mengenai penggunaan aplikasi memrise dalam pembelajaran bahasa Inggris, Tim abdimas mulai menjelaskan kegunaan dan langkahlangkah mengunakan aplikasi memrise.

Pada sesi praktek, setiap peserta membuka smartphone masing-masing. Hal pertama yang mereka lakukan adalah menginstall aplikasi memrise yang bisa diunduh secara gratis di playsore untuk pengguna android. Setelah aplikasi terpasang di handphone masing - masing peserta dapat langsung mengunakan aplikasi memrise untuk mengerjakan soal - soal TOEFL.

Hasil dari kegiatan pelatihan peningkatan kompetensi guru melalui aplikasi memrise terhadap kemampuan TOEFL adalah peserta pelatihan yang merupakan guru-guru SMPN 9 dan SMPN 34 Kota Bekasi dapat memahami konsep media pembelajaran dan fungsi media sebagai alat bantu peningkatan ketrampilan berbahasa, khusus nya penggunaan media memrise yang dapat membantu guru dalam meningkatkan kompetensi melalui TOEFL.
Luaran yang akan dihasilkan adalah guru - guru dapat menggunakan aplikasi memrise dan dapat mengerjakan soal - soal TOEFL yang nantinya terlihat dari perbandingan nilai pre - test dan post- test para guru dan selanjutnya hasil kegiatan ini akan dipublikasikan dalam jurnal.

Perbandingan score hasil pre-test dan post-test guru-guru bahasa Inggris SMPN 9 dan SMPN 34 Kota Bekasi

\begin{tabular}{|l|l|c|c|}
\hline No & \multicolumn{1}{|c|}{ Nama } & Pre-Test & $\begin{array}{c}\text { Post- } \\
\text { Test }\end{array}$ \\
\hline 1 & ANI LESTARI & 70 & 75 \\
\hline 2 & DARTA SASMITA & 70 & 78 \\
\hline 3 & $\begin{array}{l}\text { ASEP ARIS } \\
\text { SUSANTO }\end{array}$ & 73 & 80 \\
\hline 4 & SRI WINARNI & 76 & 83 \\
\hline 5 & RITA SANDRA & 78 & 85 \\
\hline 6 & AGUS HAMID & 76 & 80 \\
\hline 7 & $\begin{array}{l}\text { RIZKY } \\
\text { AGUSETIAWAN }\end{array}$ & 80 & 87 \\
\hline 8 & MARYANAH & 73 & 80 \\
\hline 9 & ENTONG SUPRIADI & 70 & 78 \\
\hline 10 & ETI MARNI & 75 & 80 \\
\hline
\end{tabular}

\section{SIMPULAN}

Untuk dapat memahami konsepkonsep pembelajaran bahasa inggris melalui media pembelajaran memrise, para peserta mengikuti kegiatan pelatihan dengan tertib dan sangat antusias dengan topik tentang peningkatan kompetensi guru melalui aplikasi memrise terhadap kemampuan TOEFL.

Hasil pengamatan berdasarkan yang dilakukan pada awal kegiatan, secara umum mengindikasikan bahwa pembelajaran bahasa Inggris di Sekolah menengah Pertama (SMP) berfokus pada pengenalan kata, pelafalan dan berbicara, membac, tatabahasa, dan menulis teks sederhana. Teknik dan media yang digunakan dapat disesuaikan dengan kondisi lingkungan sekolah. Sebagian besar peserta belum terbiasa dengan bahasa Inggris oleh karena nya bahasa Inggris hanya disisipkan percakapan sederhana dan pengenalan kata. Beberapa peserta mengeluhkan pengucapan bahasa Inggris yang perlu 
latihan terlebih dahulu sebelum mengajarkan kepada siswa.

Secara umum program pengabdian pada masyarakat yang berjudul Pelatihan peningkatan kompetensi guru melalui aplikasi memrise terhadap kemampuan TOEFL berlangsung dengan baik dan menurut para peserta pelatihan kegiatan ini sangat bermanfaat dan membentu mereka dalam pengajaran dan pengenalan bahasa Inggris. Menurut kepala sekolah SMPN 9 dan SMPN 34 Kota Bekasi dalam sambutannya di akhir kegiatan mengatakan bahwa kegiatan pengabdian seperti ini sangat mereka perlukan dan sangat bermanfaat bagi mereka dan sekiranya memungkinkan mereka meminta agar di tahun-tahun yang akan datang pengabdian seperti ini dapat lagi dilaksanakan di sekolah tersebut. Selain itu, Para guru juga merasakan banyak manfaat dari kegiatan ini.

Dari hasil evaluasi terhadap peningkatan kompetensi guru melalui aplikasi memrise terhadap kemampuan TOEFL, yang peserta lakukan di akhir kegitan terlihat bahwa para guru sudah mulai paham dan bisa meningkatkan ketrampilan berbahasa Inggris dengan aplikasi memrise walaupun dari segi teknis mereka belum terbiasa dengan pemanfaatan teknologi untuk meningkatkan kompetensi guru.

\section{DAFTAR PUSTAKA}

\author{
Barber, C. (2000). The English \\ Language: A Historical \\ Introduction. Cambridge Univ. \\ Press
}

Departemen Pendidikan Nasional. (1998). Pedoman Pelatihan Profesional Guru Sekolah Dasar. Jakarta: Depdiknas

Freeborn, D. (2006). From Old English to Standard English: A Course Book in Language Variations Across Time (Studies in English Language). New York: Macmillan.

\section{InterNet}

https://www.plti.co.id/produk-jasa/toepteflin

http://sobatbaru.blogspot.co.id/2010/03 /teori-toeic.html

http://repository.widyatama.ac.id/xmlui/ bitstream/handle/123456789/3936 Bab\%202.pdf? sequence $=7$

http://www.blue-la-goonidn.com/memrise-learn-languagesfree/\#Cara_penggunaan_Memrise https://jalantikus.com/apps/memriselearn-languages-free 